\title{
PENILAIAN SEMULA PENGAJARAN DAN PEMBELAJARAN DALAM PEMBACAAN AWAL
}

Revaluation of Teaching and Learning in Early Skills Reading

Mahzan Bin Arshad ${ }^{1}$, Chee Sook Ching ${ }^{2}$

Fakulti Bahasa dan Komunikasi, Universiti Pendidikan Sultan Idris, 35900 Tanjong Malim, Perak

mahzan@fbk.upsi.edu.my ${ }^{1}$, scchee08@gmail.com ${ }^{2}$

\begin{abstract}
ABSTRAK
Kajian ini bertujuan bertujuan untuk menilai semula pengajaran dan pembelajaran membaca Bahasa Melayu di bilik darjah prasekolah. Kajian ini menggunakan pendekatan kualitatif. Terdapat13 orang pemegang taruh, iaitu sembilan orang guru dan empat orang kanak-kanak di enam buah sekolah yang berlainan yang dipilih secara bertujuan. Data kajian dikumpul menerusi protokol temu bual dan bukti dokumen. Data tersebut dianalisis bagi memperoleh maklumat tentang amalan pengajaran Bahasa Melayu di bilik darjah prasekolah serta elemen-elemen pengajaran dan pembelajaran yang diperlukan untuk membina modul awal membaca. Dapatan kajian menunjukkan bahawa kaedah pengajaran konvensional yang diamalkan oleh kebanyakan guru gagal menarik minat kanak-kanak dalam proses pembelajaran awal membaca. Kesimpulannya, guru memerlukan bahan bantu mengajar yang bersesuiaan perkembangan kanak-kanak dengan sokongan sementara yang berpatutan. Elemen-elemen pengajaran yang perlu dimuatkan dalam modul awal membaca melibatkan pengajaran fonik, sokongan sementara dan instrumen penilaian yang autentik. Implikasinya modul MUZKAN wajar dibina untuk meningkatkan penguasaan bacaan awal kanak-kanak prasekolah dalam Bahasa Melayu.
\end{abstract}

Kata Kunci: Kemahiran membaca, muzik, gerakan, sokongan sementara, pengajaran, pembelajaran

\section{ABSTRACT}

The purpose of the study is to revaluate teaching and learning of reading Malay Language in preschool classroom. The study uses qualitative approach. There are 13 stakeholders, nine teachers and four children in six different schools were purposely selected as participants of the study. Data were collected through interview protocol and documents as evidence. The data were analized to provide information about Malay Language teaching in preschool classroom and elements that were required 
to develop early reading teaching module. Findings of the study showed that conventional method of teaching which were being used widely by teachers failed to attract children's interest in the process of teaching and learning early reading. In conclution, teachers need teaching aid materials that are suitable to temporarily support children learning. Elements of phonic instruction, temporary supporting materials and authentic assessment instruments were needed in the early reading module. The implication, Malay Language Music and Dance Module needs to be developed to enhance early reading for preschool children.

Keywords: Reading skills, music, movements, temporary support, teaching, learning

\section{PENGENALAN}

Pendidikan awal bertujuan untuk meningkatkan kemahiran, menanam keyakinan diri, membentuk konsep diri yang positif agar kanak-kanak berjaya dalam persekitaran sedia ada dan bersedia untuk menangani cabaran dan tanggungjawab di sekolah rendah kelak (KSPK, 2010). Kemahiran membaca pada peringkat prasekolah ini menggagaskan bahawa objektif KSPK (bilangan ke-14) adalah untuk melengkapkan kanak-kanak dengan kemahiran berkomunikasi menggunakan Bahasa Melayu dan bahasa pengantar dalam kehidupan harian (KSPK, 2010). Bagi memastikan objektif ini tercapai, pengajaran membaca Bahasa Melayu harus disampaikan dengan kandungan, bahan dan kaedah yang bersesuaian dengan minat, tahap kebolehan, pengalaman dan pengetahuan kanak-kanak (NAEYC, 2008). Kaedah pengajaran membaca yang memberi manfaat kepada kanak-kanak harus disampaikan melalui persekitaran pembelajaran yang selamat, menyuburkan serta aktiviti yang menyeronokkkan, kreatif dan bermakna (KSPK, 2010).

Menurut Yahya (2004), guru perlu mempelbagaikan teknik pengajaran membaca agar dapat menjadikan pengajaran lebih mempunyai variasi, menarik serta dapat menimbulkan minat murid untuk belajar. Namun, kajian oleh Resnick (2007), Marxen et al. (2008), Hoffman (2010), Mahzan Arshad (2013) telah melaporkan ketiadaan unsur keseronokan dalam proses pembelajaran membaca pada peringkat awal kanak-kanak yang mengakibatkan berlakunya masalah penguasaan kemahiran membaca. Keadaan ini menunjukkan bahawa dapatan kajian Atan Long (1986) yang mendapati kaedah membaca yang tidak berkesan menyebabkan runtuhnya minat membaca dalam kalangan kanak-kanak di Malaysia masih berlaku.

Di Malaysia, kajian Tiong dan Zaidatun Tasir (2008) menyokong kaedah lagu dan muzik dalam pengajaran dan pembelajaran kemahiran membaca bagi murid Tahun Satu di negara ini yang menekankan unsur penghayatan bahan bacaan (Yahya, 2004). Dalam kajian tersebut, didapati bahawa lagu dan aktiviti pergerakan merupakan cara yang berkesan untuk memperoleh bahasa bagi seseorang kanak-kanak yang suka menyanyi dan bergerak. Selain itu, Hanizah Abdul Bahar (2010) mendapati bahawa kecerdasan muzikal membantu kanak-kanak prasekolah dalam proses pembelajaran. Kajian Hanizah telah menyediakan hala tuju kajian ini untuk mereka bentuk modul yang menawarkan pengajaran dan pembelajaran awal membaca yang membawa keseronokan dan sifar tekanan (Aleman et. al., 2003). 


\section{PERNYATAAN MASALAH}

Berdasarkan kajian lepas tentang penggunaan muzik dan gerakan di dalam dan di luar negara, jelas menunjukkan bahawa muzik dan gerakan mempunyai kekuatan dalam meningkatkan pencapaian kemahiran bahasa. Akan tetapi, kajian lepas mendapati amalan guru masih tertumpu kepada pengajaran secara konvensional (Hoffman, 2010; Mahzan, 2013). Analisis keperluan yang dijalankan oleh penyelidik mendapati bahawa kesemua empat orang kanakkanak yang ditemu bual menyatakan kurang seronok dalam proses pengajaran dan pembelajaran membaca. Ini adalah berikutan daripada beberapa kelemahan pengajaran dan pembelajaran yang telah dikenal pasti hasil daripada temu bual dengan sembilan orang guru prasekolah yang terlibat. Menegaskan hal ini, kajian Kamisah Buang (2011) mendapati bahawa guru prasekolah masih kekurangan bahan rujukan yang merupakan punca halangan untuk menjadi lebih mahir.

\section{OBJEKTIF KAJIAN}

Secara amnya, kajian ini bertujuan untuk menilai semula pengajaran dan pembelajaran membaca Bahasa Melayu di bilik darjah prasekolah. Objektif khusus kajian ini digubal berpandukan pernyataan masalah di atas. Objektif khusus kajian ini adalah untuk:

1. menentukan amalan pengajaran dan pembelajaran membaca Bahasa Melayu di bilik darjah prasekolah.

2. mendapatkan pandangan dan cadangan pemegang taruh terhadap elemen pengajaran dan pembelajaran yang diperlukan untuk membina modul awal membaca.

\section{SOALAN KAJIAN}

Dua soalan kajian yang berikut dikenal pasti:

1. Apakah amalan pengajaran dan pembelajaran membaca Bahasa Melayu di bilik darjah prasekolah?

2. Apakah pandangan dan cadangan pemegang taruh terhadap elemen pengajaran dan pembelajaran yang diperlukan untuk membina modul awal membaca?

\section{METODOLOGI KAJIAN}

\section{Kaedah Kajian}

Kajian ini menggunakan reka bentuk kualitatif. Untuk mereka bentuk kajian ini, Model Dick dan Carey dan juga pandangan pakar serta maklum balas pemegang taruh yang terlibat telah digunakan dalam menentukan amalan pengajaran dan pembelajaran Bahasa Melayu. Analisis keperluan dijalankan untuk menilai keperluan pemegang taruh untuk membina modul MUZKAN. Kerangka kajian Fasa Analisis Keperluan ini dikemukakan pada Rajah 1. 


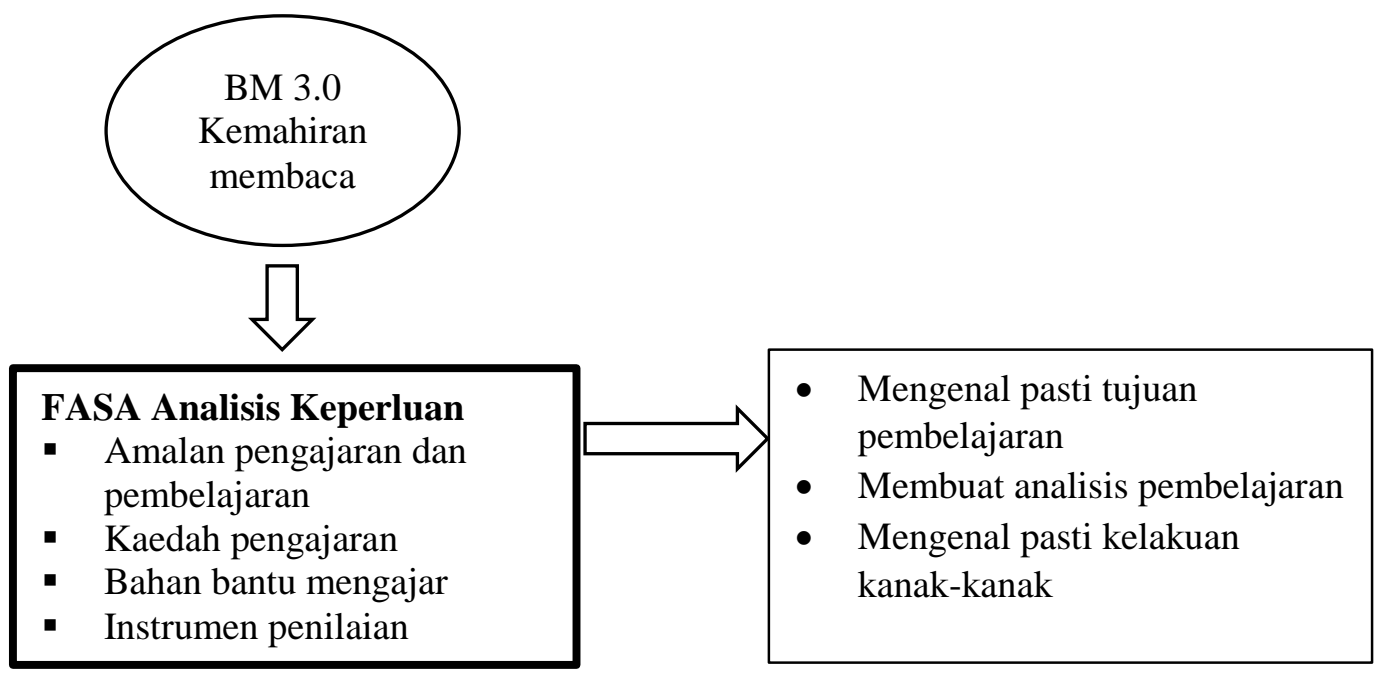

Rajah 1: Kerangka Kajian Fasa Analisis Keperluan

\section{Peserta Kajian}

Dalam Fasa Analisis Keperluan ini, pemberi maklumat melibatkan 13 orang pemegang taruh, iaitu sembilan orang guru dan empat orang kanak-kanak di enam buah sekolah yang berlainan yang dipilih secara bertujuan untuk memberi maklumat tentang amalan pengajaran Bahasa Melayu di bilik darjah prasekolah serta elemen-elemen pengajaran dan pembelajaran yang diperlukan untuk membina modul awal membaca. Guru yang menyertai kajian ini dipilih berdasarkan pengalaman dan cadangan Jurulatih Utama Prasekolah Daerah Segamat. Kanakkanak yang dipilih tersebut adalah berdasarkan kepelbagaian jantina, pencapaian akademik serta kaun Cina dan India sahaja. Pemberi maklumat ini dilibatkan bagi mendapatkan data tentang amalan dan masalah pengajaran guru prasekolah dalam subjek Bahasa Melayu di bilik darjah, dan cadangan guru dan kanak-kanak terhadap pengajaran Bahasa Melayu.

\section{Tapak Kajian}

Dalam Fasa Analisis Keperluan kajian ini, kajian awal dijalankan di Sekolah 1, Sekolah 2 dan Sekolah 3. Kesemua prasekolah ini merupakan SJKC yang mempunyai dua kelas yang mempunyai bilangan murid dalam lingkungan 15 hingga 25 orang. Selain itu, kesemua prasekolah yang dipilih terletak berhampiran dalam lingkungan lima hingga lapan kilometer. Guru-guru di prasekolah yang terlibat mudah dihubungi oleh penyelidik. Di samping itu, pihak pentadbir di sekolah yang terlibat juga memberi keizinan dan persetujuan terhadap usaha penyelidikan ini. Pihak pentadbir di ketiga-tiga sekolah juga mengalu-alukan kehadiran penyelidik di prasekolah yang memanfaatkan semua pihak. Akhir sekali, guru-guru prasekolah di Sekolah 1, Sekolah 2 dan Sekolah 3 sanggup memberi kerjasama kepada penyelidik sepanjang kajian ini.

\section{Instrumen Kajian}

Penyelidik menggunakan temu bual separa berstruktur, bukti dokumen dan pemerhatian untuk mengumpulkan data yang diperlukan untuk menentukan keperluan membina modul. 


\section{Prosedur Kajian}

Pada Fasa Analisis Keperluan, proses pengumpulan data berlaku dalam tiga peringkat untuk tempoh enam minggu bermula dari bulan Mac 2013 hingga awal bulan Mei 2013. Kebenaran pihak Guru Besar Sekolah 1, Sekolah 2 dan Sekolah 3 telah diberikan kepada penyelidik untuk membenarkan guru prasekolah untuk mengambil bahagian dalam kajian ini di luar waktu pengajaran dan pembelajaran. Pertemuan kali pertama antara penyelidik dan peserta kajian adalah untuk menerangkan tujuan kajian dan kaedah kajian. Kesahan dan kebolehpercayaan data yang diperoleh sepanjang kajian ini juga dibincang bersama dengan peserta kajian. Lawatan ini diakhiri dengan membincangkan jadual lawatan yang ditentukan berdasarkan keselesaan peserta kajian bagi tujuan temu bual dan pengumpulan bukti dokumen.

\section{DAPATAN KAJIAN}

Dapatan kajian Fasa Analisis Keperluan mendapati bahawa kebanyakan guru masih mengamalkan kaedah latih tubi secara hafalan. Kaedah ini didapati amat membosankan kanakkanak dan sering gagal menarik perhatian mereka untuk belajar membaca. Keadaan ini adalah berikutan daripada guru prasekolah tidak diberi panduan pengajaran membaca yang bersesuaian dari pihak yang berkenaan dan sering mengakibatkan kegagalan guru dalam merancang dan melaksanakan pengajaran membaca di bilik darjah prasekolah. Kebanyakan guru juga didapati jarang-jarang menggunakan bahan bantu mengajar yang lebih berpusatkan kanak-kanak. Bahan bantu mengajar yang biasa digunakan oleh guru yang ditemu bual didapati kurang berkesan kerana gagal menarik minat kanak-kanak untuk belajar membaca.

Dari aspek penilaian pengajaran pula, guru didapati kurang menggunakan bahan pentaksiran yang autentik seperti penilaian oleh kanak-kanak terhadap pencapaian sendiri. Penilaian formatif juga jarang diadakan malahan instrumen penilaian dan kekerapan menilai juga berbeza-beza dalam kalangan guru prasekolah yang ditemu bual. Standard prestasi fleksibel dan amat bergantung pada kecekapan guru untuk menilai perkembangan pencapaian kanak-kanak.

Muzik dan gerakan dianggap sebagai media pengajaran yang menarik dan mampu membantu guru dalam proses pengajaran dan pembelajaran. Menurut pandangan guru, kanakkanak lebih mudah mengingati topik pelajaran yang disampaikan oleh guru dengan adanya lagu yang boleh dinyanyikan oleh kanak-kanak secara berulang kali tanpa perlu dipaksa. Cadangan guru menyatakan bahawa kaedah muzik dan gerakan dalam pengajaran fonik Bahasa Melayu perlu digiatkan dalam kalangan guru prasekolah. Latihan atau bimbingan yang bersesuaian harus diberikan kepada para guru untuk memastikan keberkesanan pengajaran fonik dalam Bahasa Melayu. Dapatan kajian mendapati bahawa semua kanak-kanak lebih tertarik akan pembelajaran yang melibatkan aktiviti menyanyi dan bergerak.

Dari aspek sokongan sementara pula, dapatan kajian mendapati bahawa majoriti guru menyokong idea sokongan sementara dalam pengajaran dan pembelajaran membaca kerana mampu mencetuskan Kemahiran Berfikir Aras Tinggi (KBAT) dalam kalangan kanak-kanak prasekolah. Selain itu, sokongan sementara yang bersesuaian dapat meningkatkan kebolehan kanak-kanak untuk membaca pada peringkat awal. Pembelajaran koperatif dalam proses sokongan sementara juga menguntungkan kanak-kanak. 


\section{PERBINCANGAN}

\section{Perbincangan Dapatan Kajian Fasa Analisis Keperluan}

Dapatan kajian analisis keperluan mendapati bahawa aktiviti pembelajaran yang tidak berpusatkan kanak-kanak dalam pengajaran awal membaca gagal menarik minat kanak-kanak untuk membaca. Ini menjelaskan bahawa dapatan kajian Atan Long (1986), Mahzan Arshad (2013) yang mendapati kaedah membaca yang tidak berkesan ini dipercayai menyebabkan runtuhnya minat membaca dalam kanak-kanak di Malaysia masih berlaku. Ini bertepatan dengan dapatan kajian Hill-Clarke dan Robinson (2004) yang mendapati bahawa pengajaran awal membaca memerlukan kaedah yang bersesuaian dan disertai oleh variasi aktiviti yang menarik serta berpusatkan kanak-kanak. Dapatan kajian ini juga mengukuhkan lagi dapatan Isahak et. al. (2014) bahawa amalan pengajaran yang hanya mengikut urutan dan tanpa nilai keseronokan adalah membosankan kanak-kanak.

Penilaian semula pengajaran juga mendapati bahawa para guru masih mengamalkan kaedah mengajar awal membaca secara konvensional. Kebanyakan guru mengajar kanakkanak mengenal huruf dengan kaedah hafalan dan latih tubi. Maka, cadangan Piasta dan Wagner (2010) tentang keperluan kajian pengetahuan huruf secara berkesan adalah bertepatan dengan hasil kajian ini. Analisis keperluan yang mendapati bahawa guru prasekolah mengharapkan lebih banyak pengetahuan bagi meningkatkan kemahiran mereka untuk mengajar, malangnya tidak tahu bagaimana hendak memenuhi keperluan tersebut. Menegaskan hal ini, Nickel (2011) berpendapat bahawa guru harus diberi latihan dalam perkhidmatan bagi memastikan penyampaian pengajaran membaca dapat dijalankan dengan berkesan. Dapatan kajian ini juga bersesuaian dengan dapatan kajian Kamisah Buang (2011) bahawa guru prasekolah masih kekurangan bahan rujukan yang merupakan punca halangan untuk menjadi lebih mahir. Sementara itu, fenomena kekurangan kepakaran dan sumber maklumat dalam proses pengajaran dan pembelajaran adalah sejajar dengan dapatan kajian oleh Aliza Ali dan Zamri Mahamod (2015) yang mendapati guru prasekolah memerlukan sumber dan bahan pengajaran dalam bentuk modul yang memperincikan cara pengajaran dan pembelajaran kemahiran bahasa.

Selain itu, dapatan kajian ini juga mendapati bahawa majoriti guru prasekolah didapati masih kekurangan kemahiran untuk mengajar fonik dalam Bahasa Melayu walaupun sedar akan kepentingannya terhadap perkembangan kemahiran awal membaca. Guru prasekolah bersetuju bahawa pengajaran membaca dengan pendekatan fonik sesuai dipraktikkan secara sistematik dalam pengajaran awal membaca Bahasa Melayu. Keadaan ini adalah seperti kajian yang lebih awal telah mengatakan bahawa kaedah fonetik suku kata juga telah giat digunakan dalam pengajaran membaca Bahasa Melayu (Isahak, 1979; Nooraihan, 1984 dan Nik Eliani, 1997). Dapatan kajian ini bertepatan dengan Yahya Othman (2012) bahawa guru mula mengaplikasikan kaedah fonik dalam pengajaran membaca Bahasa Melayu. Ini didapati sejajar dengan tanggapan Isahak Haron et al. (2004) bahawa pengajaran membaca Bahasa Melayu harus mengambil kira sistem ejaan Bahasa Melayu yang fonemik dan suku kata yang jelas.

Di samping itu, dapatan kajian fasa ini juga telah mengenal pasti elemen-elemen pengajaran dan pembelajaran yang lebih menarik untuk dilaksanakan dalam kelas membaca. Strategi pengajaran, bahan bantu mengajar yang menarik dinyatakan oleh pemegang taruh sebagai salah satu unsur yang penting dalam menimbulkan minat kanak-kanak untuk membaca. Hasil dapatan kajian fasa ini menunjukkan bahawa kanak-kanak perlu mempunyai motivasi terhadap 
bahan bercetak seperti yang disebut dalam kenyataan Strickland (2010).

\section{KESIMPULAN}

Fasa Analisis Keperluan telah dijalankan dengan mendapatkan pandangan daripada pemegang taruh iaitu guru prasekolah dan kanak-kanak prasekolah bagi menilai semula pengajaran dan pembelajaran Bahasa Melayu di bilik darjah prasekolah. Dapatan utama yang diperoleh dalam fasa ini digunakan untuk menentukan elemen-elemen yang diperlukan dalam pembinaan modul MUZKAN.

\section{RUJUKAN}

Aleman, A., Nieuwenstein, M. R., Bocker, K. B., \& de Hann, F. H. F. (2003). Music training and mental imagery ability. Neuropsychological, 38, 1664-1668.

Aliza Ali, \& Zamri Mahmod. (2015). Pembangunan modul pendekatan bermain bagi pengajaran dan pembelajaran kemahiran bahasa kanak-kanak prasekolah. Jurnal Kurikulum \& Pengajaran Asia Pasifik, 3(1), 1-8.

Atan Long. (1986). "The importance of reading to national development". Ucapan perasmian dalam Seminar on Reading and National Development, ISIS, pada 29 April, 1986.

Hanizah Abdul Bahar. (2010). Penggunaan dan integrasi muzik dalam pengajaran dan pembelajaran di prasekolah Seri Mawar, Institut Pendidikan Guru, Kampus Ipoh: Satu kajian kes. Laporan projek Ijazah Sarjana Fakulti Seni dan Muzik, Universiti Pendidikan Sultan Idris.

Hill-Clarke, K. Y., \& Robinson, N. R. (2004). It's easy as a-b-c and do-re-mi: Music, rhythm and rhyme enhance children's literacy skills. Young Children, 59(5), 91-95.

Hoffman, J. L. (2010). Looking back and looking forward: lessons learned from Early Reading First. Childhood Education, Fall, 8-16.

Isahak Haron. (1979). Beberapa kaedah mengajar murid-murid membaca Bahasa Malaysia di peringkat awal. Kertas kerja dibentangkan di KOMPEN IV, Persatuan Suluh Budiman, Kuantan.

Isahak Haron et al. (2004). Awal membaca Bahasa Melayu: Keberkesanan kaedah gabungan bunyikata untuk prasekolah dan untuk pemulihan. Laporan projek penyelidikan jangka pendek. Fakulti Sains Kognitif dan Pembangunan Manusia. Universiti Pendidikan Sultan Idris. Tanjong Malim, Perak.

Kamisah Buang. (2013). Pembangunan dan pengujian modul intervensi membaca Bahasa Melayu prasekolah berbantukan multimedia. Tesis Dr. Falsafah Fakulti Pendidikan, Universiti Kebangsaan Malaysia.

Kurikulum Standard Prasekolah Kebangsaan. (2010). Dokumen Standard Kurikulum Prasekolah. Kementerian Pendidikan Malaysia: Bahagian Pembangunan Kurikulum.

Marxen, C., Ofstedal, K., \& Danbom, K. (2008). Highly qualified kindergarten teachers: Have they been left behind? Journal of Early Childhood Teacher Education, 29 (1), 81-88.

Mahzan Arshad (2013). Pendidikan literasi awal kanak-kanak: Teori dan amali. Perak: Penerbit Universiti Pendidikan Sultan Idris.

NAEYC. (2008). Developmentally Appropriate Practice in Early Childhood Programs Serving Children from Birth through Age 8. A positive statement of the National Association for the Education of Young Children. NW: Washington.

Nickel, J. (2011). Early childhood education students' emergent skills in literacy Scaffolding. Canadian Children, 36(1), 13-19.

Nik Eliani Nik Nawi, \& Othman Ahmad. (2009). Siri membaca cepat: Bacalah anakku. Kota Bharu: ONE-Stop Language \& Computer Consultancy.

Nooraihan Ali. (1984). Terus membaca. Kuala Lumpur: Taman Pendidikan Raihan. 
Piasta, S. B., \& Wagner, R. K. (2010). Developing early literacy skills: A meta-analysis of alphabet learning and instruction. International Reading Association, 45(1), 8-38.

Resnick, M. (2007). All I really need to know (about creative thinking) I learned (by study how children learn) in kindergarten. Kertas dibentangkan di Creativity and Cognition Conference pada Jun, 2007.

Strickland, M., \& Abbott, L. (2010). Enhancing the early reading experience: Books, strategies, and concepts. The Reading Teacher, 64(1), 66-68.

Tiong Leh Ling, \& Zaidatun Nasir. (2008). Pendekatan pembelajaran kemahiran membaca menerusi lagu dan muzik berasaskan komputer bagi murid Tahun Satu. Jurnal Penyelidikan IPBL, 8, 65-72.

Yahya Othman. (2004). Mengajar membaca: Teori dan aplikasi. Bentong: PTS Publications \& Distributors Sdn. Bhd.

Yahya Othman, Aisah Md Daud, Azmey Othman, Dk. Siti Ardiah Pg. Mohiddin, \& Maszuraimah Muizz Sulaiman. (2012). Pelaksanaan pengajaran membaca menggunakan kaedah fonik peringkat prasekolah di Brunei Darussalam. Jurnal Pendidikan Bahasa Melayu, 2(1), 93-109. 